\title{
Veredas
}

Revista de Estudos Linguísticos

https://periodicos.ufff.br/index.php/veredas/index

\section{Os usos interpessoais da conjunção "aunque" no espanhol peninsular}

\section{The interpersonal uses of the conjunction "aunque" in peninsular Spanish}

\author{
Beatriz Goaveia Garcia Parra-Araujo ${ }^{1}$ \\ Universidade Estadual Paulista - Campus de São José do Rio Preto, Brasil
}

Recebido em: 22/12/2018

Aceito em: $23 / 06 / 2020$

\section{RESUMO}

Este trabalho tem por objetivo apresentar os diferentes usos interpessoais das orações concessivas introduzidas pela conjunção aunque em textos orais do espanhol peninsular. Para tanto, adotamos como aparato teórico o modelo da Gramática Discursivo-Funcional (Hengeveld e Mackenzie, 2008), que se organiza em níveis e camadas hierárquicos, e utilizamos como córpus inquéritos de entrevistas sociolinguísticas pertencentes ao PRESEEA. Nossos resultados apontam para uma motivação funcional dos padrões relacionados à factualidade, à pressuposição, ao modo verbal e à posição das orações concessivas iniciadas por aunque que atestam a realização de estratégias interacionais de organização argumentativa por meio dessas orações, que podem tanto ressalvar um comentário anterior, guiar o ouvinte na interpretação de um enunciado posterior, como também introduzir digressões e parênteses a um discurso em andamento.

\section{PALAVRAS-CHAVE:}

Gramática Discursivo-Funcional. Orações concessivas. Conjunção aunque. Espanhol peninsular.

\section{ABSTRACT}

This work aims to present the different interpersonal uses of the concessive clauses introduced by the conjunction aunque in oral texts from the Peninsular Spanish. For this purpose, we adopted the theoretical model of the Functional Discourse Grammar (Hengeveld and Mackenzie, 2008), which is organized in hierarchical levels and layers, and we used as corpus sociolinguistic interviews belonging to PRESEEA. Our results point to a functional motivation of the standards related to factuality, presupposition, verbal mode and the position of the concessive clauses initiated by aunque that attest to the realization of interactive strategies of argumentative organization through these clauses, which can save a previous comment, guide the listener in interpreting a later statement, as well as introducing digressions and parentheses to an ongoing speech.

\section{KEYWORDS:}

Functional Discourse Grammar. Concessive clauses. Conjunction aunque. Peninsular Spanish.

\footnotetext{
${ }^{1}$ E-mail: beatriz.parra@unesp.br |ORCID: 0000-0002-4640-9325.
} 


\section{Introdução}

Uma definição comum às gramáticas tradicionais, seja em língua portuguesa (Bechara, 1999; Cunha e Cintra, 2008), seja em língua espanhola (Gili Gaya, 2000 [1943]; Alarcos Llorach, 1999), considera que uma oração concessiva é aquela que enuncia um obstáculo ao que é dito em outra oração, considerada sua principal. Nessa visão tradicional, a relação concessiva representa um caso de subordinação oracional, em que a oração subordinada concessiva depende semântica e sintaticamente da oração principal. Esse tipo de relação é ilustrado pelo exemplo a seguir, extraído da obra de sintaxe espanhola de Gili Gaya:

(01) Aunque hace mal tiempo, saldré. (Gili Gaya, 2000, p. 323)

[embora faça mal tempo, sairei] ${ }^{3}$

Segundo o autor, em uma construção concessiva como (01), a oração introduzida pela conjunção concessiva aunque afirma a existência efetiva de uma dificuldade - haver um mal tempo - para o cumprimento do que é enunciado na oração principal - sair -, mas essa dificuldade é refutada por ser ineficaz para impedir aquilo que se manifesta na oração principal.

Diversos trabalhos de caráter funcionalista, - dentre os quais mencionamos Crevels (1998, 2000a, 2000b), Neves (1999), Garcia (2010), Rosário (2012), Garcia e Pezatti (2013) e GaspariniBastos e Parra (2015) -, no entanto, contestam a validade da classificação tradicional em abarcar todas as relações introduzidas por um juntor concessivo. Os trabalhos de Crevels (1998, 2000a, 2000b), Garcia (2010) e Gasparini-Bastos e Parra (2015), por exemplo, ao analisarem a língua em contextos reais de uso, identificam orações de valor concessivo que não dependem nem semântica nem sintaticamente de uma oração anterior ou posterior a elas.

Em um estudo tipológico baseado no modelo teórico da Gramática Funcional de Dik (1997a, 1997b), Crevels (1998, 2000a, 2000b) identifica dois tipos de orações concessivas que não se enquadram na visão tradicional de concessão, conforme vemos em (02) e em (03):

\footnotetext{
${ }^{2}$ O presente trabalho foi realizado com apoio da Coordenação de Aperfeiçoamento de Pessoal de Nível Superior Brasil (CAPES) - Código de Financiamento 001.

${ }^{3}$ As traduções apresentadas neste trabalho são de minha autoria e não configuram uma reinterpretação do fenômeno descrito em espanhol para o português. Sua finalidade é simplesmente auxiliar na compreensão dos exemplos e ocorrências aqui expostos.
} 
(02) María, la carta se encuentra en el cajón - aunque estoy convencida de que ya lo sabes. (Crevels, 1998, p. 137)

[Maria, a carta está na gaveta - embora eu esteja convencida de que você já sabe disso]

(03) A: ¿A partir de qué momento ha sentido perdida su intimidad, su anonimato?

B: Todavía no me considero un personaje popular, pero creo que he perdido mi intimidad desde el momento en que, de vez en cuando, yendo por la calle, oigo que dicen mi nombre, así por detrás, o una mirada más fija que otras... aunque siempre ganas otras cosas... (Crevels, 1998, p. 140)

[A: A partir de que momento você sentiu que perdeu sua intimidade, seu anonimato?

B: Ainda não me considero uma pessoa pública, mas acho que perdi minha intimidade desde o momento em que, de vez em quando, indo pela rua, escuto que dizem meu nome, assim por trás, ou um olhar mais fixo que outros... embora sempre ganhe outras coisas...]

As orações destacadas em (02) e em (03) são denominadas pela autora orações concessivas ilocucionárias e orações concessivas textuais, respectivamente. As orações concessivas ilocucionárias (exemplo (02)) ocorrem no domínio dos atos de fala (Sweetser, 1990) e marcam uma relação conflituosa entre dois atos independentes de tal forma que o ato de fala concessivo cria um obstáculo à enunciação do ato de fala principal. Já as orações concessivas textuais (exemplo (03)) caracterizam-se por ser uma ressalva a uma porção textual precedente, composta por mais de uma oração.

Ao aplicar a proposta de classificação oferecida por Crevels (1998, 2000a, 2000b) às orações concessivas do espanhol peninsular falado introduzidas pela conjunção aunque, Gasparini-Bastos e Parra (2015) demonstram que os tipos concessivos acima expostos são ainda insuficientes para descrever as propriedades de todas as orações concessivas que representam uma estratégia interativa, pois a tipologia adotada por Crevels deixa de fora, por exemplo, os casos em que a conjunção concessiva inicia um novo tópico discursivo. Isso ocorre porque o modelo de classificação proposto por Crevels baseia-se em uma teoria que assume a oração como unidade de análise. Dessa forma, Gasparini-Bastos e Parra (2015) chamam a atenção para a necessidade de investigar as orações concessivas sob um arcabouço teórico que considere níveis de análise e domínios linguísticos mais amplos que o oracional.

Assim, este trabalho tem por objetivo apresentar uma proposta de classificação dos diferentes usos interpessoais das orações concessivas introduzidas por aunque no espanhol 
peninsular falado. ${ }^{4}$ A conjunção aunque foi escolhida para este estudo por ser apontada como o principal juntor concessivo do espanhol peninsular atual pelas gramáticas e autores normativos como a Real Academia Española (2009), Alarcos Llorach (1999) e Gili Gaya (1943-2000), bem como por pesquisadores funcionalistas (Crevels, 1998) e descritivos (Flamenco García, 1999).

Utilizamos para este estudo o aparato teórico da Gramática Discursivo-Funcional (GDF), desenvolvida por Hengeveld e Mackenzie (2008), por ser um modelo de análise que parte da intenção comunicativa para a codificação das estruturas linguísticas, o que nos permite descrever sistematicamente as propriedades pragmáticas, semânticas e morfossintáticas das orações concessivas interpessoais, bem como observar a dinâmica entre a função e a forma por elas assumida.

A fim de cumprirmos nossos objetivos, este trabalho organiza-se da seguinte forma: em 2, abordamos os princípios básicos da Gramática Discursivo-Funcional, aporte teórico sob o qual desenvolvemos esta pesquisa; em 3, contextualizamos a pesquisa aqui desenvolvida, descrevendo o córpus adotado e os fatores que guiam nossa análise; em 4, discutimos o lugar da subordinação concessiva na GDF para, em 5, focarmos nas camadas do Nível Interpessoal que são relevantes para a identificação dos casos de aunque interpessoal, cujas propriedades serão discutidas em 6. Encerramos este trabalho, em 7, com nossas considerações finais a partir dos resultados obtidos nesta pesquisa.

\section{Alguns princípios básicos da Gramática Discursivo-Funcional}

A Gramática Discursivo-Funcional (GDF) (Hengeveld e Mackenzie, 2008) é considerada uma teoria estrutural-funcional uma vez que objetiva descrever o conhecimento linguístico que possibilita a comunicação entre os usuários de uma língua, mas, ao mesmo tempo, considera que esse conhecimento é instrumental para a interação comunicativa.

A GDF apresenta-se como sendo o componente gramatical de um processo de interação verbal mais amplo, do qual também fazem parte as intenções comunicativas do falante e os aspectos contextuais relevantes para o momento da interação. Tal componente gramatical organiza-se de uma forma descendente, o que significa dizer que ele parte das intenções comunicativas e das representações mentais do falante para a estruturação dos enunciados

\footnotetext{
${ }^{4}$ A pesquisa aqui apresentada está inserida em uma investigação mais ampla - Parra (2016) - que teve por objetivo analisar as propriedades pragmáticas, semânticas e morfossintáticas das orações concessivas no espanhol peninsular falado e escrito principiadas pela conjunção aunque.
} 
linguísticos. No componente gramatical estão envolvidas duas operações fundamentais. A primeira, chamada Formulação, é responsável por traduzir o material cognitivo do falante em representações pragmáticas e semânticas. As representações pragmáticas são produzidas no Nível Interpessoal, enquanto as representações semânticas são feitas no Nível Representacional. Já a segunda operação, denominada Codificação, também se divide em dois níveis: o Nível Morfossintático, que converte as representações advindas dos níveis anteriores em estruturas morfossintáticas; e o Nível Fonológico, que codifica fonologicamente as estruturas anteriores de acordo com as regras de cada língua.

Os quatro níveis da GDF - Nível Interpessoal, Representacional, Morfossintático e Fonológico - estão organizados de modo hierárquico. Assim, o Nível Interpessoal tem primazia sobre o Representacional; estes dois, sobre o Morfossintático e todos eles sobre o Fonológico. Embora cada nível tenha sua própria estrutura, todos eles são compostos por uma série de camadas organizadas hierarquicamente.

Para ilustrar brevemente a interação entre as operações de Formulação e de Codificação, tomemos por exemplo a relação de concessão aqui estudada. Defendemos que a relação concessiva pode tanto se dar entre unidades do Nível Interpessoal, correspondendo, portanto, a uma função interpessoal; ou entre unidades do Nível Representacional, desempenhando, assim, uma função semântica. Os aspectos pragmáticos e/ou semânticos envolvidos na intenção comunicativa do falante de expressar uma concessão são codificados morfossintática e fonologicamente na operação de Codificação. Alguns aspectos morfossintáticos presentes nas orações concessivas, tais como modo verbal e posição da oração, traduzem representações voltadas para o estatuto informativo do conteúdo da oração (pressuposto ou não pressuposto), tomadas de posição do falante com relação à verdade do conteúdo expresso (factual ou não factual), entre outros aspectos.

\section{Contextualizando a pesquisa}

Para a presente pesquisa foram analisadas 138 ocorrências de aunque introduzindo orações concessivas finitas. Nosso córpus de língua falada é composto por entrevistas sociolinguísticas pertencentes ao projeto PRESEEA (Proyecto para el Estudio Sociolingüístico del Español de España y de América). Para este estudo, limitamo-nos aos inquéritos correspondentes às cidades espanholas de Alcalá de Henares, Granada, Madri e Valência por já estarem transcritos e publicados. 
A fim de descrevermos as diferentes estratégias interpessoais de aunque tanto do ponto de vista pragmático e semântico, como morfossintático, adotamos os seguintes critérios de análise:

- Informatividade da oração concessiva: Com base em Pérez Quintero (2002), consideramos que o conteúdo da oração concessiva pode ser pressuposto, quando essa oração carrega uma informação conhecida pelo ouvinte, seja porque tal informação já havia sido enunciada na interação, porque ela pode ser recuperada do contexto situacional, ou porque o falante supõe que tal informação faça parte do conhecimento de mundo do seu interlocutor; como também pode ser não pressuposto, quando a oração concessiva carrega uma informação considerada nova para o ouvinte, porque não havia sido enunciada anteriormente, porque não pode ser recuperada no contexto situacional ou porque o falante imagina que tal informação ainda não faça parte do conhecimento de mundo do seu interlocutor.

- Factualidade da oração concessiva: De acordo com Pérez Quintero (2002, p. 53), a factualidade representa um parâmetro independente, aplicável a todos os tipos de entidades linguísticas, e que distingue as orações em factuais e não factuais. Com base em Hengeveld e Mackenzie (2008, p. 144), assumimos que as orações concessivas são factuais quando expressam conhecimentos ou crenças assumidos como verdadeiros em relação ao mundo real. Já as orações concessivas não factuais expressam esperanças ou desejos que podem se realizar ou não em um mundo imaginário.

- Modo verbal da oração concessiva: Como apresentado por Flamenco García (1999, p. 3827), as orações concessivas introduzidas por aunque podem apresentar o verbo no modo indicativo ou no modo subjuntivo. O autor afirma, no entanto, que a escolha do modo verbal empregado na oração concessiva é motivada por questões de ordem pragmática e semântica, tais como a informatividade do conteúdo transmitido e a sua avaliação factual.

- Posição da oração concessiva: Como descrito por Flamenco García (1999, p. 3815) e também pela gramática da RAE (2009, p. 3602), orações concessivas podem aparecer antepostas ou pospostas a sua oração principal. Em relação à língua portuguesa, Decat (1999, p. 33-34) observa que a anteposição ou posposição das orações consideradas adverbiais, dentre elas as orações concessivas, está relacionada ao nível de dependência 
dessas orações com uma principal. Assim, as orações adverbiais tendem a ocorrer antepostas quando são dependentes semântica e sintaticamente da principal. Já quando independentes, tais orações aparecem frequentemente pospostas, visto que essa posição favorece o "desgarramento" semântico-sintática da oração ao enfatizar o conteúdo por ela descrito.

Aliada a esses critérios está a definição da camada de atuação da relação concessiva expressa por aunque tendo em vista o modelo da Gramática Discursivo-Funcional, conforme vimos na seção anterior.

Em nosso estudo, identificamos quatro possíveis camadas de atuação da relação concessiva, sendo três camadas do Nível Interpessoal e apenas uma do Nível Representacional. Descrevemos, na sequência, a concessão pertencente ao Nível Representacional, para depois focarmos nas concessivas interpessoais, alvo deste trabalho.

\section{A concessão semântica e seu lugar na GDF}

A relação concessiva que, como vimos no exemplo (01), marca uma quebra de expectativa entre uma premissa, anunciada na oração concessiva, e uma conclusão, representada na oração principal, configura uma função semântica que se dá entre essas duas orações.

Em termos de GDF, as relações semânticas são estabelecidas no Nível Representacional, nível responsável por designar as entidades linguísticas a depender do papel que essas entidades desempenham no mundo não linguístico (Hengeveld e Mackenzie, 2008, p. 130).

De acordo com Hengeveld e Mackenzie (2008, p. 54-55), a relação concessiva enquanto função semântica ocorre na camada do Conteúdo Proposicional, a mais alta dentro da estrutura hierárquica do Nível Representacional. O Conteúdo Proposicional corresponde, nos termos de Lyons (1977, p. 443), a um construto mental que não pode ser localizado nem no tempo, nem no espaço, mas apenas na mente dos participantes da comunicação.

Em nossos dados, verificamos a ocorrência de 74 orações concessivas atuantes na camada do Conteúdo Proposicional. As ocorrências a seguir ilustram esses casos:

(04) aunque era pequeño [el pueblo] hacían unas fiestas mu(y) bonitas 
(PRESEEA_GRANADA_M33_16) ${ }^{5}$

[embora o povoado fosse pequeno, faziam umas festas muito bonitas]

(05) y a ella aunque lleva muchos años por aquí pero todavía el deje sigue siendo extremeño (PRESEEA_ALCALÁ DE HENARES_H21_43)

[e quanto a ela embora esteja muitos anos por aqui, mas ainda o sotaque continua sendo da Estremadura]

Nas construções acima, a oração iniciada por aunque - "o povoado era pequeno" em (04) e "está muitos anos por aqui" em (05) - cria no ouvinte uma expectativa condicionada a essa informação; assim, em (04), imagina-se que as festas do lugar não eram muito boas, e, em (05), que a pessoa não mais apresenta o sotaque de sua região natal. No entanto, o que se afirma na oração principal contrasta com a expectativa formulada a partir da oração inicial, já que, em (04), o falante afirma que as festas realizadas eram muito bonitas, e em (05), que a mulher continuava a apresentar o sotaque típico dos falantes de Estremadura.

Quanto aos critérios de análise, as ocorrências (04) e (05) apresentam uma informação pressuposta e factual, pois expressam uma informação verdadeira já conhecida pelos interlocutores. Além disso, ambas as orações em destaque têm o verbo no modo indicativo e aparecem antepostas à oração principal.

Com base nessas ocorrências, podemos afirmar que a relação concessiva estabelecida na camada do Conteúdo Proposicional corresponde ao caso de subordinação concessiva definido ao início deste trabalho, pois, nesse tipo de relação, a oração concessiva é dependente semântica e sintaticamente da oração principal. Essa dependência é comprovada pela análise dos fatores investigados. Os resultados da análise dos fatores pragmático e semântico são apresentados na tabela 1:

\footnotetext{
${ }^{5}$ As referências que acompanham as ocorrências são compostas pelo nome do projeto (PRESEEA), seguido pelo nome da cidade onde foi realizada a coleta, o sexo do informante ( $\mathrm{M}$ para mulher e $\mathrm{H}$ para homem), o código que o identifica e o número do inquérito.
} 
Tabela 1 - Análise da informatividade e da factualidade nas concessivas semânticas

\begin{tabular}{|c|c|c|c|c|}
\hline & \multicolumn{2}{|c|}{ Informatividade } & \multicolumn{2}{|c|}{ Factualidade } \\
\hline & Pressuposta & Não pressuposta & Factual & Não factual \\
\hline $\begin{array}{l}\text { Número de } \\
\text { ocorrências }\end{array}$ & $32(43,2 \%)$ & $42(56,8 \%)$ & $36(48,6 \%)$ & $38(51,4 \%)$ \\
\hline
\end{tabular}

As orações concessivas que estabelecem uma concessão semântica tendem a transmitir uma informação não pressuposta, embora também sejam frequentes os casos pressupostos. Com relação à factualidade, seu conteúdo pode ser factual, como não factual. Exemplos de concessivas factuais foram vistos em (04) e em (05), enquanto as ocorrências (06) e (07) ilustram exemplos não factuais:

(06) aunque no seas una persona muy constante tienes que tener algo de disciplina/ porque si no// si no trabajas hoy (PRESEEA_GRANADA_H32_09)

[mesmo que você não seja uma pessoa muito constante, tem que ter um pouco de disciplina, porque senão não trabalha hoje]

(07) pero si es una señora / que veo por la calle / aunque sea de mi edad la llamo de usted (PRESEEA_MADRI_M23_34)

[mas se é uma senhora que vejo pela rua, mesmo que seja da minha idade a chamo de senhora]

Nas ocorrências anteriores, observamos que o falante cria uma situação hipotética e por isso o Conteúdo Proposicional introduzido por aunque não pode ser considerado nem verdadeiro, nem falso, mas apenas possível de se realizar. Além de serem não factuais, as ocorrências (06) e (07) transmitem uma informação não pressuposta, pois a realização ou não de tais hipóteses não é conhecida previamente pelos interlocutores. Ambas as ocorrências também apresentam o verbo da oração concessiva no modo subjuntivo e a oração introduzida por aunque aparece em posição anteposta.

Com relação aos aspectos morfossintáticos, os números apresentados na tabela 2 revelam que as concessivas de Conteúdo Proposicional podem levar o verbo no indicativo ou no subjuntivo, predominando este último. Com relação à posição, as orações concessivas introduzidas por aunque, quando exercem uma função semântica, tendem a ocorrer antepostas à 
principal, ainda que se verifiquem alguns casos pospostos, como em (08):

Tabela 2 - Análise do modo verbal e da posição nas concessivas semânticas

\begin{tabular}{|c|c|c|c|c|}
\hline & \multicolumn{2}{|c|}{ Modo verbal } & \multicolumn{2}{|c|}{ Posição } \\
\hline & Indicativo & Subjuntivo & Anteposta & Posposta \\
\hline $\begin{array}{l}\text { Número de } \\
\text { ocorrências }\end{array}$ & $27(36,5 \%)$ & $47(63,5 \%)$ & $60(81,1 \%)$ & $14(18,9 \%)$ \\
\hline
\end{tabular}

(08) voy a pedir un crédito particular a un banco voy a transformar mi tienda o a reformar mi / $\mathrm{mi}$ vivienda / aunque me cueste un poco más caro (PRESEEA_ALCALÁ DE HENARES_H32_33) [vou pedir um crédito particular a um banco, vou transformar minha loja ou reformar minha casa mesmo que me custe um pouco mais caro]

Embora as orações concessivas da camada do Conteúdo Proposicional sejam a maioria em nosso córpus e tenham adquirido o status de oração concessiva prototípica graças às definições apresentados pelas gramáticas tradicionais, que identificam o fenômeno da concessão apenas como um caso de subordinação oracional, tais orações correspondem a apenas um dos tipos concessivos possíveis de serem introduzidos pela conjunção aunque em espanhol.

As demais 64 ocorrências levantadas em nossa análise não se enquadram nas definições apresentadas para as concessivas de Conteúdo Proposicional por diferirem tanto no que diz respeito a sua funcionalidade, quanto as suas propriedades de ordem pragmática, semântica e morfossintática. Tendo em vista que nosso enfoque é oferecer uma classificação a esses outros tipos de orações concessivas que são pouco explorados ou, muitas vezes, sequer conhecidos, conferiremos maior atenção ao Nível Interpessoal e às camadas desse nível que são relevantes para nossa análise.

\section{As camadas de atuação da relação concessiva no Nível Interpessoal}

O Nível Interpessoal é o mais alto dentro da hierarquia de níveis proposta pela GDF e representa as estratégias linguísticas desempenhadas durante a interação para que os objetivos comunicativos do falante sejam compreendidos pelo ouvinte. Como descreve Keizer (2015, p. 49), esse é o nível responsável por ilustrar as atitudes assumidas pelo falante na construção de um enunciado linguístico. Verificamos em nossa análise que, nesse nível, a concessão pode atuar nas 
camadas do Movimento, do Ato Discursivo e da llocução.

O Movimento é a camada mais alta do Nível Interpessoal, considerada a maior unidade interacional relevante para a análise linguística na GDF. Em termos de seu estatuto interpessoal, o Movimento é definido como uma contribuição autônoma para uma interação em andamento e sua principal propriedade é o fato de exigir uma reação comunicativa ou ser ele mesmo essa reação. (Hengeveld e Mackenzie, 2008, p. 50).

Segundo Kroon (1997, p. 20), é possível identificar um Movimento por duas propriedades inerentes a ele: a primeira é que um Movimento corresponde a uma unidade comunicativa, isto é, ao maior "bloco" informacional passível de ser delimitado pelo modelo da GDF; já a segunda propriedade é que um Movimento também corresponde a uma unidade temática, ou seja, todos os elementos que o compõem devem ser tematicamente coerentes.

Os Movimentos também podem ocorrer inseridos dentro de outros Movimentos, isto é, como um parêntese a um Movimento principal. De acordo com Hengeveld e Mackenzie (2008, p. 52), esse segundo tipo de Movimento relaciona-se pragmaticamente ao Movimento que interrompe uma vez que visa a acrescentar uma informação ou um comentário pessoal sobre o tópico que estava sendo desenvolvido.

Dentro da arquitetura da GDF, um Movimento compõe-se por um ou mais Atos Discursivos, definidos por Kroon (1997, p. 20) como a menor unidade identificável do comportamento comunicativo. A principal diferença entre o Ato Discursivo e o Movimento é o fato de que o Ato Discursivo não tem o compromisso de promover a comunicação, podendo, em um contexto de interação face a face, encorajar o falante a continuar com o seu turno, atuando como uma voz de fundo, vazia de conteúdo informativo e que não gera progresso na comunicação. (Hengeveld e Mackenzie, 2008, p. 50).

De acordo com Hengeveld e Mackenzie (2008, p. 63), um Ato Discursivo é constituído por quatro elementos, são eles: a llocução, o Falante, o Ouvinte e o Conteúdo Comunicado, sendo obrigatórios apenas os dois primeiros. Em (09), oferecemos um exemplo de Ato Discursivo:

(09) O homem vendeu sua casa para o comprador.

Em (09), vemos que ao Ato Discursivo apresenta uma llocução declarativa, pois, ao proferilo, o falante tem por objetivo acrescentar uma nova informação ao conhecimento de mundo do seu ouvinte. Keizer (2015, p. 66) define Ilocução como uma forma convencional de expressar a 
intenção comunicativa por trás do Ato Discursivo. Se abstrata, a llocução pode ser, além da declarativa, imperativa, interrogativa, entre outros tipos definidos por Hengeveld e Mackenzie (2008, p. 71-72).

\section{Tipos concessivos interpessoais introduzidos por aunque}

Como dito na seção anterior, identificamos relações concessivas marcadas pela conjunção aunque ocorrendo em três camadas que compõem o Nível Interpessoal: a camada do Movimento, do Ato Discursivo e da llocução. A atuação da relação concessiva nas camadas do Movimento e do Ato Discursivo já havia sido atestada para o português pelos estudos de Garcia (2010) e de StassiSé (2012), sendo que o segundo tipo - concessivas de Ato Discursivo - está previsto na própria GDF. Já as orações concessivas de llocução, terceiro tipo identificado, não são mencionadas nesses trabalhos anteriores voltados para a descrição das concessivas em GDF.

$\mathrm{Na}$ tabela 3, a seguir, oferecemos o número de ocorrências de cada um dos tipos concessivos interpessoais identificados:

Tabela 3 - As orações concessivas introduzidas por aunque em relação à camada de atuação no Nível Interpessoal

\begin{tabular}{cc}
\hline Camada de atuação & Número de ocorrências \\
\hline Movimento & $15(23,4 \%)$ \\
Ato Discursivo & $35(54,7 \%)$ \\
Ilocução & $14(21,9 \%)$ \\
TOTAL & 64 \\
\hline
\end{tabular}

Na sequência, detalharemos cada um dos tipos concessivos interpessoais, bem como suas propriedades pragmáticas, semânticas e morfossintáticas.

\subsection{A relação concessiva na camada do Movimento}

Tendo em vista que o Movimento é uma unidade interacional comunicativamente completa e tematicamente coerente, para identificarmos as orações que atuam nessa camada nos baseamos em Jubran (2006a, 2006b) quanto ao desenvolvimento dos tópicos discursivos. Nesse 
sentido, observamos que as concessivas de Movimento introduzidas por aunque caracterizam-se por interromper bruscamente o desenvolvimento linear de um tópico anterior, fenômeno este conhecido por descontinuidade tópica.

Segundo Jubran (2006a, p. 100), três fenômenos são responsáveis por gerar descontinuidade tópica: a ruptura, a cisão e a expansão. Observamos em nossos dados que as orações introduzidas por aunque exercem tanto a ruptura como a cisão tópica. Nos casos de ruptura tópica, o Movimento em andamento é suprimido e um novo tópico é introduzido no Movimento precedido por aunque. Nesses casos, o tópico interrompido não é retomado e a interação comunicativa converge para o novo tópico inserido no Movimento concessivo. Vejamos a seguinte ocorrência:

(10) E: ¿Y ahora en qué consiste tu trabajo?

I: [... ] mi trabajo consiste yo ahora mismo soy jefe de de la sección de producción/// del centro de proceso de datos/ y la sección de producción se encarga/// de/ de emitir los productos finales [...] eso es un poco/ el trabajo/ que al final consiste fundamentalmente en/ en estar/// eso es en facilitar que la gente pueda digo la gente/ los programadores los analistas/ pues/ tengan información sobre lo que está pasando y puedan/ actuar fundamentalmente eso o sea// al final haces un trabajo/ más o menos burocrático// aunque yo siempre digo una cosa que como yo a mí no se me puede olvidar// lo que lo que tengo que saber para ejercer de lo que soy que es analista de aplicaciones/ yo todos los años tengo que hacer tres programas/ cuando llegue final de año yo tengo que haber hecho tres programas/ y los hago ¿eh?
E: Pero ¿porque te lo piden o porque tú quieres? (PRESEEA_GRANADA_H32_07)
[E: e agora em que consiste o seu trabalho?

I: [...] meu trabalho consiste eu agora sou chefe da seção de produção do centro de processamento de dados e a seção de produção se encarrega de emitir os produtos finais [...] um pouco o trabalho ao final consiste fundamentalmente em facilitar que as pessoas possam, digo, os programadores, os analistas tenham informação sobre o que está acontecendo e possam atuar, fundamentalmente, ou seja, ao final você faz um trabalho mais ou menos burocrático, embora eu sempre diga uma coisa que eu não posso esquecer o que tenho que saber para exercer aquilo que sou que é analista de aplicações, eu todos os anos tenho que fazer três programas e os faço, viu. E: mas por que te pedem ou por que você quer?] 
Em (10), observamos que o tópico discursivo no qual o entrevistado define o seu trabalho é interrompido pela inserção de um novo Movimento por meio da conjunção aunque e que contém por tópico o compromisso do entrevistado de criar três programas de computador por ano. $\mathrm{O}$ tópico suprimido não é retomado e a pergunta do entrevistador ¿porqué te lo piden o porqué tú quieres? encaminha a interação para o desenvolvimento do novo tópico.

Nos casos de cisão, por sua vez, a oração introduzida por aunque pode atuar como uma inserção ou um parêntese ao interromper momentaneamente o Movimento em andamento. 0 Movimento introduzido pelo juntor concessivo pode apresentar um tópico paralelo ao que estava sendo desenvolvido no Movimento anterior, no caso da inserção, ou promover uma breve supressão ainda vinculada à temática desenvolvida no Movimento interrompido, no caso do parêntese. Observemos a seguinte ocorrência:

(11) el fin de semana que viene// lo tengo libre// bueno tengo guardia el viernes/ salgo el sábado a las nueve y media// o a las diez// y tengo/ sábado y domingo lo tengo libre/// porque ya el/ siguiente// tengo/ el sábado me toca guardia en el centro de salud/// al siguiente tengo un viaje/ aunque ese es más de hobby que de otra cosa/ pero en fin/ también// también gusta/ y al siguiente tengo un curso (PRESEEA_GRANADA_M32_10)

[tenho o final de semana que vem livre, bom tenho plantão na sexta, saio no sábado às nove e meia ou às dez, e tenho sábado e domingo livres, porque já no próximo tenho plantão no sábado no centro de saúde, já no próximo tenho uma viagem, embora isso é mais de hobby que de outra coisa, mas enfim, eu também gosto, e no seguinte tenho um curso]

Em (11) temos que o Movimento no qual a informante discorre sobre sua agenda nos próximos finais de semana é momentaneamente interrompido pelo Movimento parentético principiado por aunque, no qual o falante explica que a viagem referida não é um compromisso de trabalho, mas sim uma atividade de lazer, contrastando, dessa forma, com as atividades laborais descritas no Movimento anterior.

Ao constituírem unidades comunicativas isoladas, as orações introduzidas por aunque pertencentes à camada do Movimento são desgarradas, nos termos de Decat (1999), ou independentes, nos termos de Garcia (2010), em relação a um escopo. Assim, as concessivas de Movimento apenas se relacionam pragmaticamente com um conjunto de enunciados anteriores, apresentado, portanto, autonomia semântica e sintática. 
Tal independência pode ser notada a partir da análise dos fatores adotados para esta pesquisa, conforme vemos nas tabelas 4 e 5 :

Tabela 4 - Análise da informatividade e da factualidade nas concessivas de Movimento

\begin{tabular}{|c|c|c|c|c|}
\hline & \multicolumn{2}{|c|}{ Informatividade } & \multicolumn{2}{|c|}{ Factualidade } \\
\hline & Pressuposta & Não pressuposta & Factual & Não factual \\
\hline Número de ocorrências & $4(26,7 \%)$ & $11(73,3 \%)$ & $15(100 \%)$ & - \\
\hline
\end{tabular}

No que diz respeito à factualidade, os resultados expostos na tabela 4 revelam que todas as orações concessivas de Movimento são factuais. Quanto à informatividade, são identificadas tanto concessivas de Movimento com informação não pressuposta, representadas pelas ocorrências anteriores, como concessivas com informação pressuposta, representadas a seguir:

(12) con la edad que tiene que son cincuenta y/ dos años / que ya / tendría que dejar de fumar porque dentro de supongo que de cuatro días le empezará a salir cosas raras de la sangre/ se destruye eeh tendrá obstruidas ya las venas pero luego tendrá problemas / está el cáncer // tendría que decirle todo eso y explicárselo / y bueno supongo que lo sabrá pero que no no quiere verlo / al igual que yo tampoco quiero verlo / y tampoco quiero bueno tengo veinticuatro años // aunque siempre es malo fumar a cualquier edad ¿no? / pero que tampoco quiero abrir los ojos y por ahora tampoco yo no me planteo dejar de fumar / y mi padre sí / mi padre se lo ha plan planteao muchas veces dejar de fumar / pero tampoco le pone mucha voluntad (PRESEEA_VALENCIA_H13_20)

[com a idade que tem que são cinquenta e dois anos que já teria que deixar de fumar porque dentro de suponho quatro dias começará a sair coisas estranhas do sangue, terá as veias obstruídas, mas logo terá problemas, está aí o câncer, teria que dizer a ele tudo isso e lhe explicar, e bom suponho que o saberá mas que não o quer ver, como eu que também não quero ver, e também não quero bom tenho vinte e quatro anos, embora sempre é mal fumar em qualquer idade, né?, mas também não quero abrir os olhos por enquanto e também não planejo deixar de fumar, e meu pai sim, meu pai já planejou muitas vezes deixar de fumar, mas também não coloca muita vontade nisso] 
Os aspectos morfossintáticos das concessivas de Movimento estão resumidos na tabela 5:

Tabela 5 - Análise do modo verbal e da posição nas concessivas de Movimento

\begin{tabular}{|c|c|c|c|c|}
\hline & \multicolumn{2}{|c|}{ Modo verbal } & \multicolumn{2}{|c|}{ Posição } \\
\hline & Indicativo & Subjuntivo & Anteposta & Posposta \\
\hline Número de ocorrências & $14(93,3 \%)$ & $1(6,7 \%)$ & - & $15(100 \%)$ \\
\hline
\end{tabular}

Verificamos pelos dados apresentados que as concessivas introduzidas por aunque, quando atuam na camada do Movimento, apresentam, em geral, verbo no modo indicativo, como ilustram as ocorrências (10), (11) e (12), sendo raros os casos com subjuntivo. Já a posição dessas orações é sempre posposta, tendo em vista que as orações concessivas da camada do Movimento atuam como uma ressalva ou um comentário acrescentado ao Movimento iniciado anteriormente.

\subsection{A relação concessiva na camada do Ato Discursivo}

Para Hengeveld e Mackenzie (2008, p. 52), os Atos Discursivos pertencentes a um mesmo Movimento podem estabelecer entre si uma relação de dependência entre o Ato considerado Nuclear e um ou mais Atos Subsidiários, que exercerão uma função retórica com relação ao Ato Nuclear. A relação concessiva que se estabelece entre dois ou mais Atos Discursivos é considerada um tipo de função retórica, pois está relacionada à interação entre os participantes da comunicação.

Segundo Keizer (2015, p. 61), a função retórica concessão ocorre quando o falante utiliza o Ato Subsidiário para admitir que o conteúdo do Ato Nuclear não é algo esperado. Assim, ao atuarem como estratégia para garantir que o ouvinte interprete as intenções comunicativas do falante, as orações concessivas introduzidas por aunque que atuam na camada do Ato Discursivo estão intrinsecamente voltadas à realização do Ato Discursivo Nuclear, estabelecendo uma ressalva ao todo ou a algum elemento específico do Ato Nuclear que não tenha sido utilizado de modo adequado no contexto, conforme vemos nas ocorrências (13) e (14):

(13) pues busqué a/ a uno de los cuidadores/ de los animales del parque porque no solamente está el pavo real hay ciervos aunque eso sí están encerra(d)os (PRESEEA_GRANADA_M31_06) [pois procurei um dos cuidadores de animais do parque, porque não tem só o pavão, tem cervos, 
embora isso sim estejam fechados]

(14) mi instituto tiene fama/ tiene cierto prestigio de ser uno de los mejores institutos aunque yo no creo demasiado en ese tema (PRESEEA_GRANADA_M33_17)

[o meu instituto tem a fama, tem certo prestígio de ser um dos melhores institutos embora eu não creia muito nesse tema]

As orações iniciadas por aunque em destaque atuam como uma ressalva ao Ato Nuclear enunciado anteriormente. Assim, em (13), após dizer que no parque havia também outros animais além do pavão, o falante comenta que os cervos ficavam fechados para evitar que seu ouvinte pensasse que tais animais também andassem soltos pelo parque como o pavão. Também em (14), o falante, ao dizer que seu instituto é considerado um dos melhores, sente a necessidade de atenuar essa informação, acrescentando, por meio da oração concessiva, sua opinião contrária a tal prestígio.

Nas construções concessivas pertencentes à camada do Ato Discursivo, a oração concessiva e a oração principal são Atos distintos e com independência de llocução. Portanto, é possível inserir nas orações introduzidas por aunque apresentadas anteriormente uma expressão performativa como "eu admito que" (yo admito que): 6

(13') hay ciervos aunque (yo admito que) eso sí están encerra(d)os.

$\left(14^{\prime}\right)$ mi instituto tiene fama/ tiene cierto prestigio de ser uno de los mejores institutos aunque (yo admito que) no creo demasiado en ese tema.

As propriedades das orações concessivas de Ato Discursivo introduzidas por aunque são muito próximas das propriedades das orações concessivas de Movimento. Os resultados da análise da informatividade e da factualidade dessas orações são apresentados na tabela 6, a seguir:

\footnotetext{
${ }^{6}$ Segundo Hengeveld e Mackenzie (2008, p. 54), a possibilidade de inserir uma expressão performativa em uma oração concessiva evidencia o caráter interacional dessa oração.
} 
Tabela 6 - Análise da informatividade e da factualidade nas concessivas de Ato Discursivo

\begin{tabular}{lcccc}
\hline & \multicolumn{2}{c}{ Informatividade } & Factualidade \\
\cline { 2 - 4 } & Pressuposta & Não pressuposta & Factual & Não factual \\
Número de ocorrências & $17(48,6 \%)$ & $18(51,4 \%)$ & $35(100 \%)$ & - \\
\hline
\end{tabular}

Quando atuam na camada do Ato Discursivo, a oração encabeçada por aunque é sempre factual e pode expressar um conteúdo não pressuposto - como ilustrado pelas ocorrências (13) e (14) -, ou um conteúdo pressuposto, como ilustrado em (15):

(15) luego me subí al Zulema / ya más alejado claro y además dependiendo de Villalbilla aunque yo seguía trabajando en Alcalá yo bajaba como si fuera / aquello de Zulema fuera una barriada que en realidad lo es de Alcalá aunque pertenezca al municipio de Villalbilla (PRESEEA_ALCALÁ DE HENARES_H33_51)

[logo subi ao Zulema, já mais distante claro e mais dependente de Villalbilla embora eu seguisse trabalhando em Alcalá eu descia como se Zulema fosse uma periferia que em realidade o é de Alcalá embora pertença ao município de Villalbilla]

Na codificação morfossintática dessas orações, predomina o uso do modo indicativo ocorrências (13) e (14) - frente ao subjuntivo - ocorrência (15). E a única posição assumida por essas orações é a posposta, conforme vemos na tabela 7, a seguir:

Tabela 7 - Análise do modo verbal e da posição nas concessivas de Ato Discursivo

\begin{tabular}{|c|c|c|c|c|}
\hline & \multicolumn{2}{|c|}{ Modo verbal } & \multicolumn{2}{|c|}{ Posição } \\
\hline & Indicativo & Subjuntivo & Anteposta & Posposta \\
\hline Número de ocorrências & $23(65,7 \%)$ & $12(34,3 \%)$ & - & $35(100 \%)$ \\
\hline
\end{tabular}

Tendo em vista que a oração concessiva pertencente à camada do Ato Discursivo está intimamente vinculada à enunciação do Ato Discursivo Nuclear, consideramos que a posição assumida por tais orações representa morfossintaticamente a função retórica por elas desempenhada. 


\subsection{A relação concessiva na camada da llocução}

Os resultados da análise dos tipos concessivos interpessoais introduzidos por aunque apresentados comprovam para os dados do espanhol peninsular o que outros estudiosos - Garcia (2010), Stassi-Sé (2012), Garcia e Pezatti (2013) - já haviam atestado para o português: a existência de relações concessivas na camada do Ato Discursivo e do Movimento. Nossos dados, por sua vez, revelam a ocorrência de um outro tipo concessivo até então não tratado sob o arcabouço teórico da GDF: a relação concessiva que se localiza na camada da llocução. Vejamos a seguinte ocorrência:

(16) muy bien// aunque eres joven pero/ ¿hay algo que te hubiera gustado hacer que no hayas hecho? (PRESEEA_VALENCIA_M412_01)

[muito bem, embora você seja jovem, há algo que você gostaria de ter feito e que não fez?]

Nessa ocorrência, ao reconhecer a jovialidade do ouvinte, o entrevistador sabe que seu interlocutor poderá ainda realizar muitas coisas que não realizou, e, portanto, julga inadequado interrogá-lo sobre o que ele gostaria de ter feito em sua vida, como se esta já estivesse próxima do fim. Assim, na tentativa de preservar a sua face e de motivar o ouvinte a responder o questionamento proposto, o falante apresenta primeiramente a oração concessiva, na qual ele admite a jovialidade do entrevistado para, em seguida, realizar a pergunta.

Em ocorrências como (16), a oração concessiva não faz uma ressalva ao conteúdo transmitido por um Ato Discursivo, mas se volta para o modo como ele é enunciado, ou seja, para a sua força ilocucionária, atuando como um modificador de sua llocução. Assim, a ocorrência (16) poderia ser parafraseada da seguinte forma: "eu sei que você é jovem e que, por isso, pode fazer muitas coisas na sua vida, mas, apesar desse fato, pergunto se há algo que você gostaria de ter feito e ainda não fez".

Quanto às suas propriedades pragmáticas e semânticas, as concessivas de llocução introduzidas por aunque sempre retomam uma informação pressuposta e factual, conforme ilustram as ocorrências a seguir: 
(17) A: ¿te gusta cocinar?

B: no/// lo odio// mi marido es cocinero [...]

A: bien/ ¿cómo prepararías una fiesta familiar?// es decir/ aunque no te guste cocinar/ imagínate que vas a preparar el cumpleaños de tu hija. (PRESEEA_VALENCIA_MC111_01)

[A: você gosta de cozinhar?

B: não, odeio, meu marido é cozinheiro [...]

A: como você prepararia uma festa familiar? ou seja, embora você não goste de cozinhar imagine que vai preparar o aniversário da sua filha]

(18) y aunque estamos en fiestas navideñas/ ¿cómo ves el futuro? (PRESEEA_VALENCIA_MC132_96)

[e embora estejamos na época natalina, como você vê o futuro?]

As duas ocorrências apresentadas contêm uma oração introduzida por aunque cujo conteúdo é pressuposto porque já havia sido enunciado no contexto textual precedente (ocorrência (17)), ou porque faz parte do contexto situacional em que ocorre a interação (ocorrência (18)).

A análise também indica que as orações concessivas de llocução ocorrem tanto no modo subjuntivo, como ilustramos em (17), como no modo indicativo, como ilustramos em (18). Embora os dois modos sejam frequentes, o indicativo prevalece com relação ao subjuntivo, conforme vemos na tabela a seguir:

Tabela 8 - Análise do modo verbal nas concessivas de llocução

\begin{tabular}{lcc}
\hline & \multicolumn{2}{c}{ Modo verbal } \\
\cline { 2 - 3 } Número de ocorrências & $10(71,4 \%)$ & Subjuntivo \\
\hline
\end{tabular}

Pezatti (2014, p. 113), ao estudar a ordem das palavras na língua portuguesa de um ponto de vista funcionalista, afirma que os modificadores de llocução tendem a vir antes da oração que escopam. Em nossa análise, observamos que todas as orações concessivas de llocução encontradas localizam-se antepostas à oração principal. Assim, no caso das orações concessivas introduzidas por aunque, consideramos que a anteposição é a codificação morfossintática que 
caracteriza o tipo concessivo desempenhado por essas orações.

\section{Considerações Finais}

Neste trabalho, objetivamos apresentar uma proposta de tipificação das orações concessivas introduzidas por aunque que configuram usos interpessoais da relação concessiva.

Por meio da análise de 138 ocorrências de aunque extraídas de textos orais do espanhol peninsular, observamos que, desse total, 74 ocorrências se encaixam na definição tradicional de subordinação concessiva, enquanto as outras 64 ocorrências não configuram casos de subordinação concessiva, conforme definido pelas gramáticas tradicionais tanto do espanhol como do português, por não estabelecerem uma relação de dependência semântica e sintática com sua oração principal.

Valendo-nos do modelo teórico da Gramática Discursivo-Funcional, que se estrutura em níveis e camadas hierarquicamente dispostos e parte da intenção comunicativa para a codificação das expressões linguísticas, buscamos uma classificação para as diferentes relações concessivas estabelecidas por aunque.

Assim, as 74 ocorrências que atuam como casos de subordinação concessiva e que se enquadram na definição tradicional de concessão atuam no Nível Representacional, mais especificamente na camada do Conteúdo Proposicional. Essas orações representam a concessão como uma função semântica que marca uma quebra de expectativa entre premissas e conclusões. Dada sua natureza epistêmica, essas orações podem transmitir conteúdos factuais e não factuais. Morfossintaticamente, a dependência semântica que existe entre subordinada e principal é marcada por uma dependência sintática entre essas duas orações, que se configura por meio do predomínio do modo subjuntivo na oração introduzida por aunque e em sua posição anteposta.

As 64 ocorrências que fogem a esse padrão são casos representativos de uma relação concessiva que se estabelece no Nível Interpessoal, podendo atuar na camada do Movimento, do Ato Discursivo ou da llocução.

Quando a oração concessiva é pertencente à camada do Movimento, a conjunção aunque tem por função interromper - definitiva ou momentaneamente - um Movimento em andamento para introduzir um novo tópico discursivo ou um comentário relacionado ao tópico em desenvolvimento. Nesses contextos de uso, a conjunção aunque é esvaziada de seu papel de juntor subordinativo para atuar como um recurso coesivo que auxilia na organização interacional. Com base nas categorias propostas por Hengeveld e Mackenzie (2008, p. 52), quando marca uma 
relação concessiva de Movimento, aunque corresponde a um operador do tipo push, isto é, uma forma gramatical responsável por introduzir digressões e inserções.

Já quando localizada na camada do Ato Discursivo, a relação concessiva configura uma função retórica que tem por finalidade introduzir, por meio de aunque, uma ressalva a um Ato Discursivo anterior. Por meio da ressalva representada pela oração concessiva encabeçada por aunque, o falante busca evitar interpretações equivocadas e possíveis objeções por parte do ouvinte.

Tanto nos casos de Movimento como nos de Ato Discursivo, a oração concessiva introduzida por aunque é independente semântica e sintaticamente da oração que a acompanha. Essa independência é marcada pelo fato de o conteúdo da oração concessiva ser sempre factual e, em termos morfossintáticos, predominar o uso do modo indicativo e a posição sempre ser a posposta.

O terceiro tipo interpessoal de relação concessiva possivel de ser marcado pela conjunção aunque é aquele que se estabelece na camada da llocução. Nesses casos, a oração introduzida pela conjunção concessiva tem uma função restritiva que indica ao ouvinte o modo como ele deve interpretar o Ato que segue. As orações concessivas de llocução caracterizam-se por serem factuais, por expressarem um conteúdo pressuposto pelos interlocutores e por apresentarem verbo predominantemente no modo indicativo.

Os resultados ainda demonstram que as orações concessivas de llocução sempre ocorrem antepostas à oração principal, posição que, como vimos, também é predominante nas orações concessivas de Conteúdo Proposicional. Essa semelhança entre a concessão interpessoal da camada da llocução e a concessão semântica está relacionada ao fato de que, em ambos os contextos, a oração concessiva iniciada por aunque atua como um modificador da oração principal, ao contrário das concessivas de Movimento e de Ato, que atuam como adendos e, por isso, ocupam a posição posposta. Assim, a anteposição das orações concessivas codifica morfossintaticamente o papel de modificador desempenhado por elas, seja na camada da llocução, quando localizadas no Nível Interpessoal, seja na camada do Conteúdo Proposicional, quando localizadas no Nível Representacional.

Nossa análise aponta, portanto, o uso interpessoal da concessão marcada pela conjunção aunque como estratégia linguística dos usuários do espanhol peninsular, e demonstra que as propriedades pragmáticas, semânticas e morfossintáticas dessas orações revelam importantes aspectos do processo comunicativo, tais como o planejamento da argumentação, a antecipação 
de objeções, o jogo de imagens entre os interlocutores e a organização dos conteúdos dentro do texto no uso das orações concessivas.

\section{Referências}

ALARCOS LLORACH, E. Gramática de la Lengua Española. Madrid: Espasa, 1999.

BECHARA, E. N. Moderna gramática da língua portuguesa. 37. ed. Rio de Janeiro: Lucerna, 1999.

CREVELS, M. Concession in Spanish. In: HANNAY, M.; BOLKESTEIN, A. M. Functional Grammar and verbal interaction. Amsterdam: John Benjamins, 1998. p. 129-148.

CREVELS, M. Concession: a typological study. 2000. 191 p. Tese (Doutorado) - Faculty of Humanities, University of Amsterdam, Amsterdam, 2000a.

CREVELS, M. Concessives on different semantic levels: a typological perspective. In: COUPERKUHLEN, E.; KORTMANN, B. (Ed.). Cause, condition, concession, contrast cognitive and discourse perspectives. Berlin: Mouton de Gruyter, 2000b. p. 313-339.

CUNHA, C; CINTRA, L. F. L. Nova gramática do português contemporâneo. 5. ed. Rio de Janeiro: Lexicon, 2008.

DECAT, M. B. N. Por uma abordagem da (in)dependência de cláusulas à luz da noção de "unidade informacional". SCRIPTA, Belo Horizonte, v. 2, n. 4, p. 23-38, jan/jun. 1999.

DIK, S. C. The theory of Functional Grammar. Part 1: The Structure of the Clause. HENGEVELD, K. (Ed.). 2. ed. Berlin: Mouton de Gruyter, 1997a.

DIK, S. C. The theory of Functional Grammar. Part 2: Complex and Derived Constructions. HENGEVELD, K. (Ed.). 2. ed. Berlin: Mouton de Gruyter, 1997b.

FLAMENCO GARCÍA, L. Las construcciones concesivas y adversativas. In: BOSQUE, I.; DEMONTE, V. (Org.). Gramática descriptiva de la lengua española. Madrid: Espasa-Calpe, v. 3: Entre la oración y el discurso, 1999. p. 3805-3878.

GASPARINI-BASTOS, S. D.; PARRA, B. G. G. Uma investigação funcional da conjunção aunque em dados do espanhol falado peninsular. Revista de Estudos da Linguagem, Belo Horizonte, v. 23, n. 1, p. 127-158, 2015.

GARCIA, T. S. As relações concessivas no português falado sob a perspectiva da Gramática Discursivo-Funcional. 2010. 176 f. Tese (Doutorado em Estudos Linguísticos) - Instituto de Biociências, Letras e Ciências Exatas, Universidade Estadual Paulista, São José do Rio Preto, 2010.

GARCIA, T. S. G.; PEZATTI, E. G. Orações concessivas independentes à luz da Gramática DiscursivoFuncional. Alfa, São Paulo, v. 57, n. 2, p. 475-494, 2013.

GILI GAYA, S. Curso superior de sintaxis española. Barcelona: Vox, 1943-2000.

HENGEVELD, K.; MACKENZIE, J. L. Functional Discourse Grammar: a typologically-based theory of language structure. Oxford: Oxford University Press, 2008.

JUBRAN, C. C. A. S. Tópico discursivo. In: JUBRAN, C. C. A. S.; KOCH, I. G. V. Gramática do português culto falado no Brasil. Campinas, SP: Editora da UNICAMP, v. 1: construção do texto falado, $2006 a$. p. 89-132. 
JUBRAN, C. C. A. S. Parentetização. In: JUBRAN, C. C. A. S.; KOCH, I. G. V. Gramática do português culto falado no Brasil. Campinas, SP: Editora da UNICAMP, v. 1: construção do texto falado, 2006b. p. 301-357.

KEIZER, E. A Functional Discourse Grammar for English. Oxford Textbooks in Linguistics. Oxford: Oxford University Press, 2015.

KROON, C. Discourse markers, discourse structure and Functional Grammar. In: CONNOLLY, J. et al (Ed.). Discourse and pragmatics in functional grammar. Berlin: Mouton de Gruyter, 1997. p. 17-32.

LYONS, J. Semantics. Cambridge: Cambridge University Press, v. 2, 1977.

NEVES, M. H. M. As construções concessivas. In: NEVES, M. H. M. (Org.). Gramática do português falado. São Paulo: Humanitas/FFLCH/USP; Campinas: Editora da UNICAMP, v. 7: Novos estudos, 1999. p. 545-591.

PARRA, B. G. G. Uma investigação discursivo-funcional das orações concessivas introduzidas por aunque em dados do espanhol peninsular. 2016. 169 f. Dissertação (Mestrado em Estudos Linguísticos) - Instituto de Biociências, Letras e Ciências Exatas, Universidade Estadual Paulista, São José do Rio Preto, 2016.

PÉREZ QUINTERO, M. J. Adverbial Subordination in English: a functionalist approach. Amsterdam: Rodopi, 2002.

PEZATTI, E. G. A ordem das palavras no português. São Paulo: Parábola, 2014.

REAL ACADEMIA ESPAÑOLA; ASOCIACIÓN DE LAS ACADEMIAS DE LA LENGUA ESPAÑOLA. Nueva gramática de la lengua española. Madrid: Espasa Libros, v. 2: Sintaxis II, 2009.

RODRÍGUEZ ROSIQUE, S. From discourse to grammar: when the Spanish incluso meets a si conditional. Lingvisticae Investigationes, n. 35, p. 94-119, 2012. Disponível em: <http://connection.ebscohost.com/c/articles/85660864/from-discourse-grammar-when-spanishincluso-meets-si-conditional>. Acesso em: 24 jul 2015.

ROSÁRIO, I. C. Expressão da concessividade em construções do português do Brasil. 2012. $271 \mathrm{f}$. Tese (Doutorado em Línguas Vernáculas) - Faculdade de Letras, Universidade Federal do Rio de Janeiro, Rio de Janeiro, 2012.

STASSI-SÉ, J. C. Subordinação discursiva no português à luz da gramática discursivo-funcional. 2012. 194 f. Tese (Doutorado em Estudos Linguísticos)-Instituto de Biociências, Letras e Ciências Exatas, Universidade Estadual Paulista, São José do Rio Preto, 2012.

SWEETSER, E. E. From etymology to pragmatics. Metaphorical and cultural aspects of semantic structure. Cambridge: Cambridge University Press, 1990. 